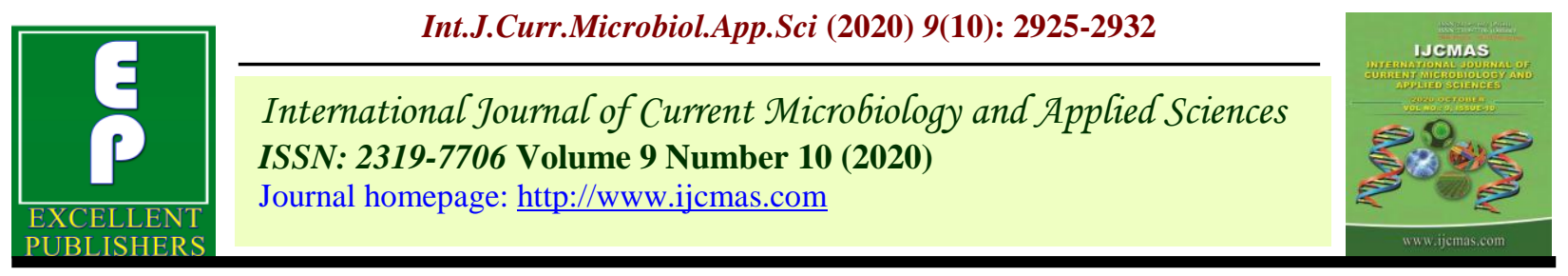

Original Research Article

https://doi.org/10.20546/ijcmas.2020.910.352

\title{
Electrical Analysis of Solar Photovoltaic-Thermoelectric Generator Hybrid System
}

\author{
Parul Mertia*, Surendra Kothari, N. L. Panwar, Deepak Sharma and Sunil Joshi \\ Department of Renewable Energy Engineering, Maharana Pratap University of Agriculture \\ and Technology, Udaipur, Rajasthan, India \\ *Corresponding author
}

\section{A B S T R A C T}

\section{Keywords}

Solar PV, TEG, Efficiency

Article Info

Accepted:

24 September 2020

Available Online:

10 October 2020
A Solar Photovoltaic-Thermoelectric generator hybrid system is analyzed in the present study. The experimental setup was examined under Udaipur climatic conditions $\left(24^{\circ} 35^{\prime} 7^{\prime \prime} \mathrm{N} ; 7^{\circ} 42^{\prime} 45^{\prime \prime} \mathrm{E}\right)$. The I-V, P-V characteristics and efficiency of sub systems and hybrid system were estimated. The ambient temperature, the solar irradiation, the PV module surface and rear temperature, hot and cold side temperature of TEG, wind velocity affects the performance of the system. The overall efficiency of hybrid system was observed to be higher than the PV system alone.

\section{Introduction}

With the increase in energy requirement and problems like pollution, climate change, global warming, demand for clean and sustainable energy and especially solar energy has been increased over the past decade [1]. This solar energy can be easily harnessed in usable forms, like, electricity and thermal energy. The photovoltaic (PV) systems are used for direct conversion of solar energy into electrical energy through photovoltaic effect and the thermoelectric generators (TEG) through Seebeck effect converts the thermal energy directly into electrical energy[2]. These electricity generation systems offer various advantages like pollutant free during operation, low maintenance, no chemical reactions, long lifetime, and no moving parts [3]. This conversion of solar energy into usable forms needs to be efficient. The PV system offers a conversion efficiency of only $10-15 \%$ sincethe thermalization and absorption losses are more than $50 \%$ of incident solar radiation and they convert between $6 \%$ and $25 \%$ of irradiation into electricity and rest is dissipated as heat. The energy band-gap of semiconducting material is absorbing the energy of the visible and some low wavelength portion of infrared spectrum and remaining energy of the spectrum is dissipated as thermal energy which results in temperature rise of PV module above ambient. The dark saturation 
current at the $\mathrm{p}-\mathrm{n}$ junction increases with increase in intrinsic carrier concentration due to high temperature of PV cell and the overall electrical power of the PV system decreases by $0.2-0.5 \%$ for every $1{ }^{\circ} \mathrm{C}$ rise in the PV module temperature $[4,5]$.In order to cool the PV system and utilize this waste heat, a number of combined photovoltaic and heat recovery systems have been proposed by many researchers. Li et al., [6] presented a detailed review of solar photovoltaicthermoelectric hybrid system for electricity generation studied by many researchers by categorizing the types of systems discussed into spectrum splitting photovoltaicthermoelectric system and integrated photovoltaic-thermoelectric system. Elsarrag et al., [7] utilized a beam splitter and placed it at an angle of $45^{\circ}$ to both the PV and TEG to split the incident solar radiation. This spectrum splitter split the wavelength of irradiation into favorable wavelength for PV and TEG. Deng et al., [8] integrated a silicon thin-film solar cell (STC), thermoelectric generators (TEGs) and a heat collector for power generation. Wu et al., [9] compared the performance of a glazed and unglazed photovoltaic-thermoelectric (PV-TE) hybrid system and used nanofluid as a heat sink and to increase the heat removal from the system.

Taking the following considerations, an experimental investigation was carried out to utilize the waste heat generated in Solar PV module by integrating it with a Thermoelectric generator under climatic conditions of Udaipur region.

\section{Materials and Methods}

\section{System Description}

The experimental investigation was carried at the Department of Renewable Energy Engineering, Maharana Pratap University of Agriculture and Technology, Udaipur
(Rajasthan) India $\left(24^{\circ} 35^{\prime} 7^{\prime \prime} \mathrm{N} ; 73^{\circ} 42^{\prime} 45^{\prime \prime} \mathrm{E}\right)$ and at an altitude of $582.5 \mathrm{~m}$ above meansea level). The study was performed in the month of May under the real atmospheric conditions. The Solar Photovoltaic-Thermoelectric Generator hybrid system consists of a $5 \mathrm{~W}$ Solar Photovoltaic module, 6 Thermo-electric Generator modules, and two different sets of heat sink (toothed fin type and straight fin type;six each). In this hybrid system the series connected TEG modules are sandwiched between PV module and Heat sink. The hot side of the TEG assembly was thermally attached at rear side of PV module while the cold side of the TEG assembly was attached to the aluminum heat sink. The technical specifications of solar panel used are presented in Table 1 and the specifications for commercially available TEG module used are presented in Table 2. The values of input parameters used for further analysis of the hybrid system are given in Table 3.

In this study, two different types of heat sink having different types of fins were tested for optimized combination. The heat sink having better results was used in order to dissipate the heat and to maintain the temperature difference. Both the heat sinks used were made of aluminum and had a size same as of the TEG modules of $40 x 40 \mathrm{~mm}$ so that they were perfectly fitted. However the heat sinks differ in terms of base plate thickness, size and shape of fins. The toothed fin type heat sink had a base plate thickness of $2.2 \mathrm{~mm}$ with fins arranged in a matrix of $13^{\times} 10$ having length of $11 \mathrm{~mm}$ and thickness of $1.1 \mathrm{~mm}$ while the straight fin type heat sink had a base plate thickness of $4 \mathrm{~mm}$ and 11 fins of $20 \mathrm{~mm}$ length. Further the two subsystems (PV module and TEG module) were analyzed and discussed in sequence to clarify the working process in terms of electrical performance of the PV-TEG hybrid system. The performance and overall efficiency of the PV-TE hybrid system depends on a series of parameters such 
as the ambient temperature, the solar irradiation, the PV module surface and rear temperature, hot and cold side temperature of TEG, wind velocity.

\section{Solar Photovoltaic Module}

PV module is characterized by its I-V and P$\mathrm{V}$ characteristics and the system efficiency. The efficiency is defined as the ratio of the maximum power output of solar cell to the power input of incident solar radiation. In general the percentage of the energy that is converted into electrical energy is the module's efficiency. Energy efficiency of solar PV system will be calculated by (Sahin et al., [10])

$\eta=\frac{P_{m}}{P_{r a d}}$

$\eta_{P V}=\frac{V_{a c} I_{S C F}}{G A_{P V}}$

Where Fill Factor (FF)is given by Solanki [11]

$\mathrm{FF}=\frac{\mathrm{P}_{\mathrm{m}}}{\mathrm{V}_{\mathrm{oc}} \mathrm{I}_{\mathrm{gc}}}$

\section{Thermoelectric element}

The behavior of the thermoelectric generator is characterized by the figure of merit (ZT) given as [12]:

$Z T=\frac{\alpha^{2} \sigma}{k} T$

where $\sigma$ represents the electrical conductivity, $\mathrm{k}$ is the thermal conductivity and $\alpha$ is the Seebeck coefficient. The dimensionless thermoelectric coefficient for the selected TEG module is 1.5.The efficiency of the thermoelectric element was calculated and is given by Cotfas et al., [13]
$\eta_{T E}=\frac{T_{H}-T_{C}}{T_{H}} \frac{\sqrt{1+Z T}-1}{\sqrt{1+Z T}+\frac{T_{C}}{T_{H}}}$

Where $T_{H}$ and $T_{C}$ are the temperature of the hot side and the cold side of the TE module, respectively.

\section{Results and Discussion}

To analyze the energy generation from Solar PV and Thermoelectric generator system in actual use under climatic conditions of Udaipur region, an experiment was conducted. The results obtained by plotting the Energy extraction characteristics for both subsystems and hybrid system, power and efficiency obtained for the system using formulae presented in materials and methods are presented graphically (Fig. 1-4).

Only a fraction of solar radiation was converted into electricity by the PV module while most of its part was converted into heat and the TEG module utilized the low-grade heat and directly generated electric power. It is clear from Fig. 1-4 that due to change in incident radiation on the PV module, the current and voltage of the module gets changed. The PV module showed maximum Power of $3.9 \mathrm{~W}$ when Current was maximum $0.396 \mathrm{~A}$ at Voltage of $9.85 \mathrm{~V}$. The TEG module showed maximum Power of 775.08 $\mathrm{mW}$ when Current was maximum $5.23 \mathrm{~mA}$ at Voltage of $148.2 \mathrm{mV}$. The efficiency of PV module increase with decrease in incident solar radiations and the average efficiency was $8.63 \%$.The average efficiency of TEG modules was $0.2 \%$. The highest output power obtained in PV-TEG hybrid system was $5.25 \mathrm{~W}$ and the net increase in output power was found to be $18.5 \%$ when compared with PV Module output.

The Series connected TEG modules were analyzed with both types of heat sink and the toothed fin type heat sink showed better 
power output than the straight fin type heat sink. This result is well matched with Ekpu et al., [14] as reported that better heat dissipation occurred in thinner base and extended fins height for both aluminum and copper heat sinks but the aluminum heat sink recorded the lowest minimum temperatures.
The power output of series connected TEG modules with toothed fin type heat sink was $0.09 \mathrm{~W}$ higher than the TEG assembly with straight fin type heat sink. The results shown here are for the system with the toothed fin type heat sink assembly.

Table.1 Specification of the PV system

\begin{tabular}{|l|c|}
\hline \multicolumn{1}{|c|}{ Parameter } & Value \\
\hline Number of Cells & 18 \\
\hline Type of Cells & Polycrystalline \\
\hline Maximum Power $\left(\mathbf{P}_{\mathbf{m}}\right)$ & 5 \\
\hline Maximum Power Voltage $\mathbf{V}_{\mathbf{m}}$ & $17.8 \mathrm{~V}$ \\
\hline Maximum Power Current $\mathbf{I}_{\mathbf{m}}$ & $0.28 \mathrm{~A}$ \\
\hline Open Circuit Voltage $\mathbf{V}_{\mathbf{~ o c}}$ & $22.3 \mathrm{~V}$ \\
\hline Short Circuit Current $\mathbf{I}_{\mathbf{s c}}$ & $0.3 \mathrm{~A}$ \\
\hline Fill Factor $(\mathbf{F F})$ & 0.74 \\
\hline Dimensions & $24 \mathrm{~cm} \mathrm{x} 16 \mathrm{~cm}$ \\
\hline
\end{tabular}

Table.2 Specification of the PV system

\begin{tabular}{|l|c|}
\hline \multicolumn{1}{|c|}{ Parameter } & Value \\
\hline Dimension & $40 \mathrm{~mm} \times 40 \mathrm{~mm} \times 3.6 \mathrm{~mm}$ \\
\hline Maximum Operating Temperature, Tmax & $0-150^{\circ} \mathrm{C}$ \\
\hline Open Circuit Voltage $\mathbf{V}_{\text {oc }}$ & $4.8 \mathrm{~V}$ \\
\hline Current & $20^{\circ} \mathrm{C} / 0.97 \mathrm{~V} / 225 \mathrm{~mA} ;$ \\
& $40^{\circ} \mathrm{C} / 1.8 \mathrm{~V} / 368 \mathrm{~mA} ;$ \\
& $60^{\circ} \mathrm{C} / 2.4 \mathrm{~V} / 469 \mathrm{~mA} ;$ \\
& $80^{\circ} \mathrm{C} / 3.6 \mathrm{~V} / 559 \mathrm{~mA} ;$ \\
\hline Module Resistance & $100^{\circ} \mathrm{C} / 4.8 \mathrm{~V} / 669 \mathrm{~mA}$ \\
\hline Wire Length & $0.323 \mathrm{Ohms}$ \\
\hline Material & $350 \mathrm{~mm}$ \\
\hline
\end{tabular}

Table.3 Input parameters used for research work

\begin{tabular}{|l|c|}
\hline \multicolumn{1}{|c|}{ Input Parameters } & Values \\
\hline Nominal operating cell temperature (NOCT) & $40^{\circ} \mathrm{C}$ \\
\hline Boltzmann's Constant (k) & $1.38 \times 10-23 \mathrm{~J} / \mathrm{K}$ \\
\hline Stefan Boltzmann Constant $(\boldsymbol{\sigma})$ & $5.67 \times 10^{-8} \mathrm{Wm}^{-2} \mathrm{~K}^{-4}$ \\
\hline Emissivity of the front surface of PV module (8) & 0.91 \\
\hline Area of PV module & $0.0384 \mathrm{~m}^{2}$ \\
\hline Area of TEG module & $0.0096 \mathrm{~m}^{2}$ \\
\hline
\end{tabular}


Fig.1 I-V and P-V Characteristics of Solar PV Module
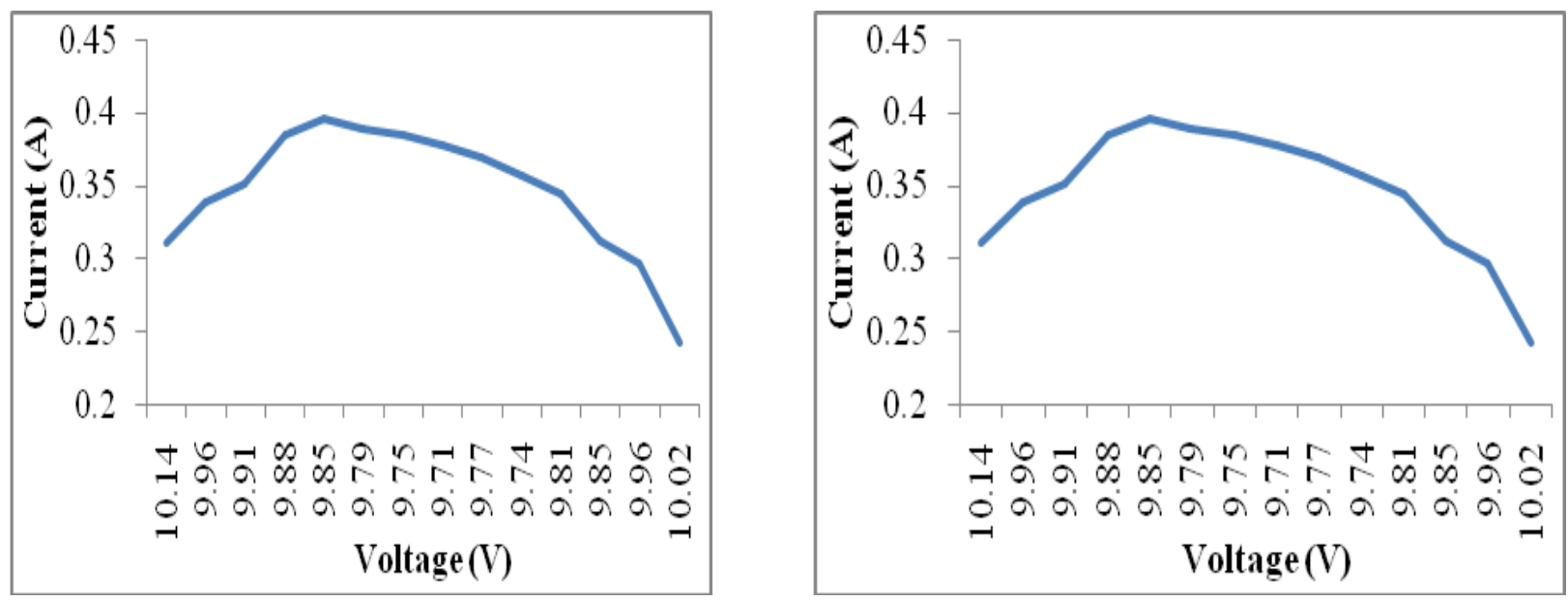

Fig.2 I-V and P-V Characteristics of TEG Module
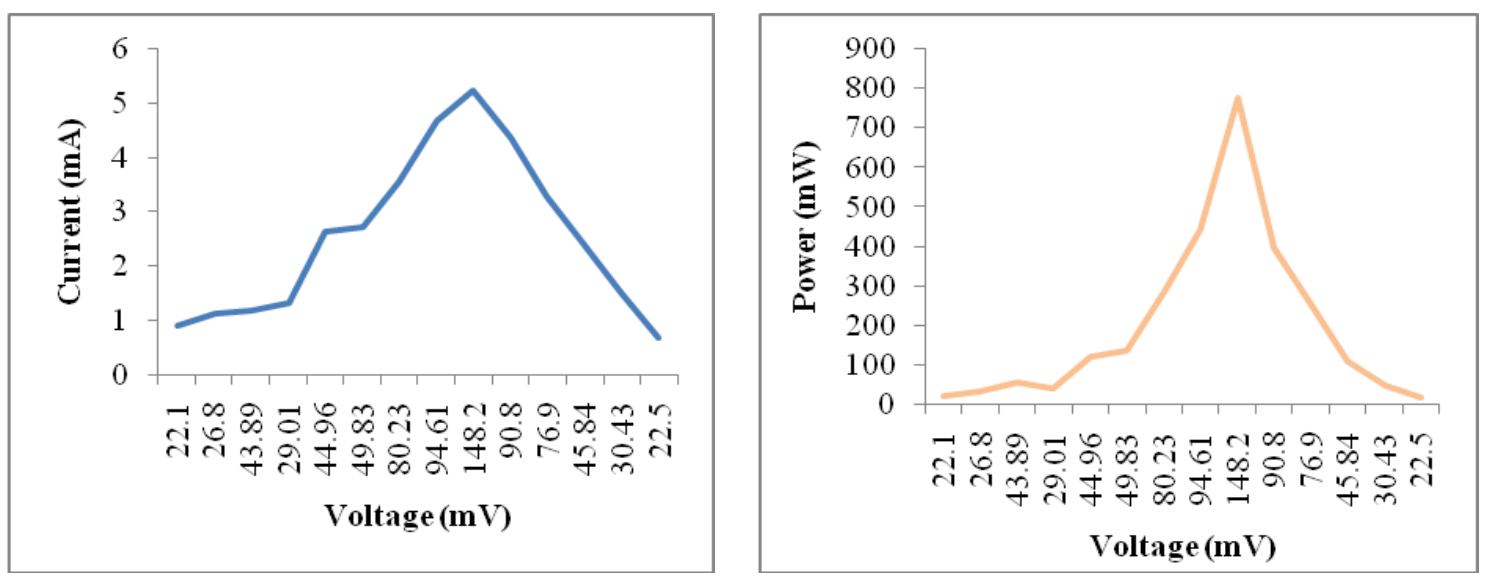

Fig.3 Efficiency of PV and TEG Module
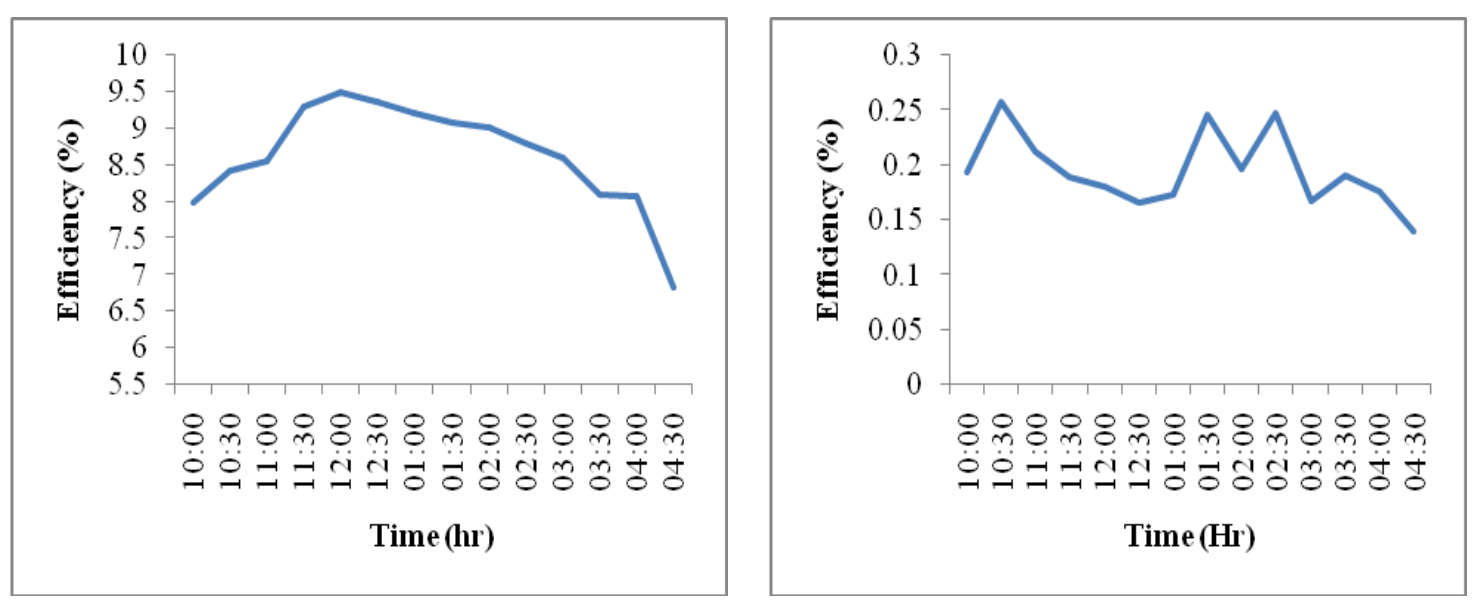
Fig.4 Power of Solar Photovoltaic-Thermoelectric generator hybrid system

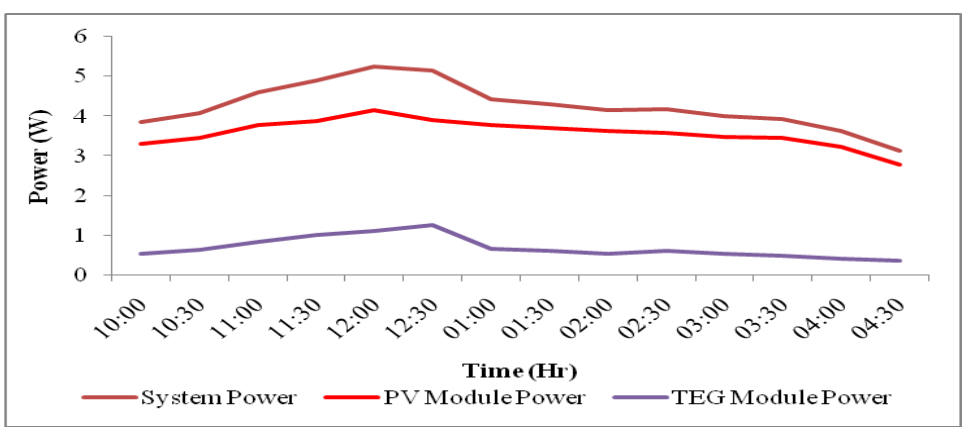

Fig.5 Variation of Solar PV Module Temperature with Solar Radiation

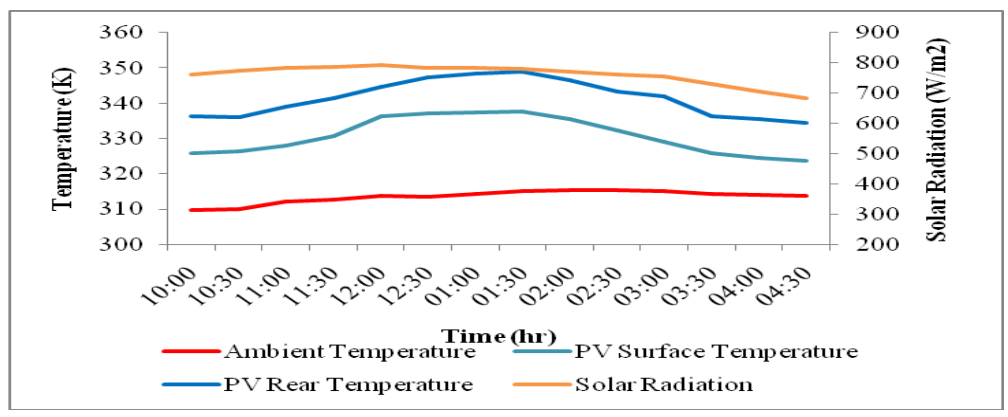

Fig.6 Variation of Solar PV Module Temperature with Wind Speed

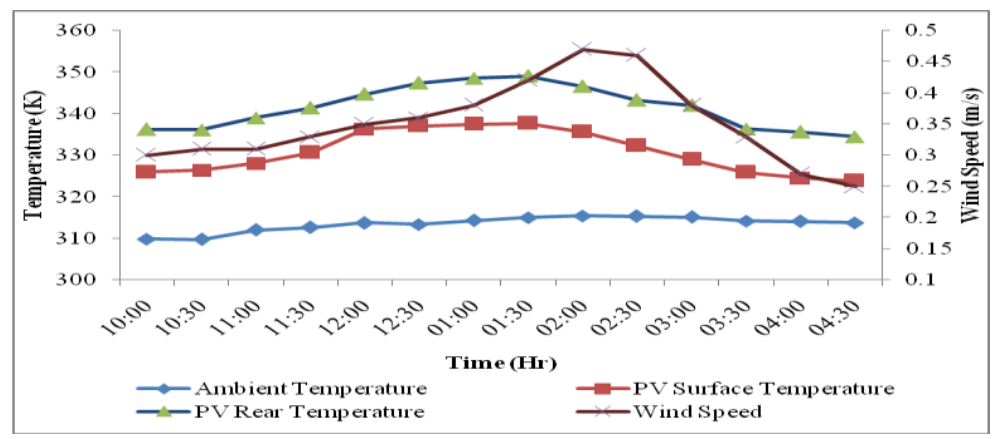

Fig.7 Temperature Profile of Solar Photovoltaic-Thermoelectric generator hybrid system

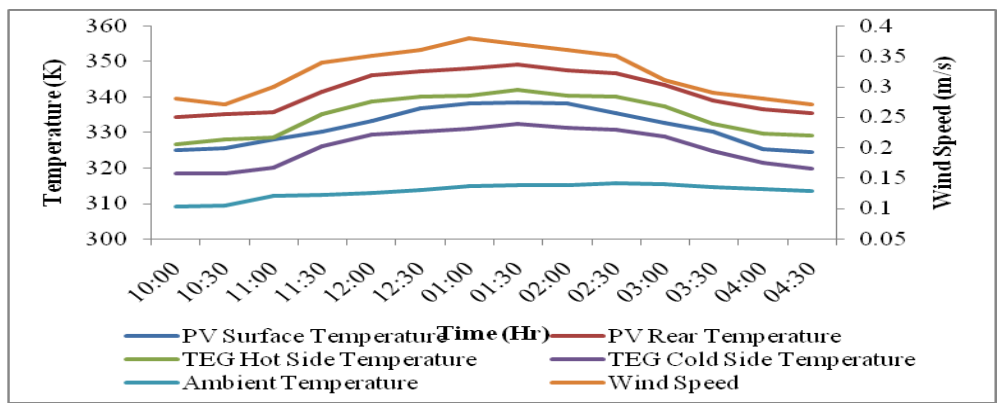


The temperature profiles of Solar PV module and hybrid system with respect to solar radiation and wind speed are presented graphically (Fig. 5-7). It was observed that the temperature of the rear side of the PV Module was always higher than its surface temperature and the average difference in temperature between both sides of PV module was $10.72 \mathrm{~K}$. With increase in wind speed and decrease in incident radiations both the temperatures of PV module and TEG module i.e. surface and rear side temperature of PV module and hot and cold side temperature of TEG module decreases. The averagetemperature difference between the hot and the cold side of TEG modules was $2.68 \mathrm{~K}$.

In conclusion the overall efficiency of PV system depends on its temperature. The rear side temperature of PV module was found to be always higher than the surface temperature. This provided a scope to utilize this high temperature and generate a small power through TEG module and heat sink. From the study it was also found that the direct integration of such components at the rear side of PV module helps in improvement of overall efficiency. The heat sink assembly with toothed fins helped to increase the area and provided a greater heat transfer.

\section{References}

1. Beeri, O., Rotem, O., Hazan, E., Katz, E.A., Braun, A., and Gelbstein, Y. Hybrid photovoltaic-thermoelectric system for concentrated solar energy conversion: Experimental realization and modeling, 2015, Journal of Applied Physics, vol. 118, no. 11, pp. 1151049(1-8).

2. Li, G., Chen, X., and Jin, Y. Analysis of the Primary Constraint Conditions of an Efficient Photovoltaic-Thermoelectric Hybrid System, 2017, Energies, vol. 10, no. 20.

3. Siecker, J., Kusakana, K. and Numbi, B.P. A review of solar photovoltaic systems cooling technologies, 2017, Renewable and Sustainable Energy Reviews, vol. 79, pp. 192-203.

4. Lamba, R. and Kaushik, S.C. Modeling and performance analysis of a concentrated photovoltaicthermoelectric hybrid power generation system, 2016, Energy Conversion and Management, vol. 115, pp. 288-298.

5. Noro, M., Lazzarin, R., and Bagarella, G. Advancements in hybrid photovoltaic-thermal systems: performance evaluations and applications, 2016, Energy Procedia, vol. 101, pp. 496 - 503.

6. Li, G., Shittu, S., Diallo, T.M.O., Yu, M., Zhao, X. andJi, J. A review of solar photovoltaic-thermoelectric hybrid system for electricity generation, 2018, Energy, vol. 158, pp. 41-58.

7. Elsarrag, E., Pernau, H., Heuer, J., Roshan, N., Alhorr, Y. and Bartholome, K. Spectrum splitting for efficient utilization of solar radiation: a novel photovoltaic-thermoelectric power generation System, Renewables, vol. 2, no. 16.

8. Deng, Y., Zhu, W., Wang, Y., and Shi, Y. Enhanced performance of solardriven photovoltaic-thermoelectric hybrid system in an integrated design, 2013, Solar Energy, vol. 88, pp. 182191.

9. Wu, Y.Y., Wu, S.Y., and Xiao, L. Performance analysis of photovoltaicthermoelectric hybrid system with and without glass cover, 2015, Energy Conversion and Management, vol. 93, pp. 151-159.

10. Sahin, A. D., Dincer, I. and Rosen, M. A. Thermodynamic analysis of solar photovoltaic system.2007 Solar Energy Materials and Solar Cells vol. 91, pp. 
153-159.

11. Solanki, C.S. Solar Photovoltaic: Fundamentals, Technologies and Applications. 2012, PHI Learning Pvt. Ltd., New Delhi pp. 324-388.

12. Jarman, J.T., Khalil, E.E. andKhalaf, E. Energy Analyses of Thermoelectric Renewable Energy Sources, 2013,Open Journal of Energy Efficiency, vol. 2, pp. 143-153.

13. Cotfas, P. A., Cotfas, D. T., Machidon, O. M., and Ciulavu, C., Performance evaluation of the thermoelectric generator. In: Proceedings of the
International Conference on Scientific Research and Education in the Air Force, AFASES, held at Romania in 2016, pp. 239-246.

14. Ekpu, M., Bhatti, R., Ekere, N., Mallik, S., Amalu, E, and Otiaba, K. Investigation of Effects of Heat Sinks on Thermal Performance of Microelectronic Package. In: Proceedings of $3^{\text {rd }}$ IEEE International Conference on Adaptive Science and Technology (ICAST) in 2011, pp.127132.

\section{How to cite this article:}

Parul Mertia, Surendra Kothari, N. L. Panwar, Deepak Sharma and Sunil Joshi. 2020. Electrical Analysis of Solar Photovoltaic-Thermoelectric Generator Hybrid System. Int.J.Curr.Microbiol.App.Sci. 9(10): 2925-2932. doi: https://doi.org/10.20546/ijcmas.2020.910.352 